CULTURE TECHNIQUES FOR ACANTHOPS FALCATA, A NEOTROPICAL MANTID SUITABLE FOR BIOLOGICAL STUDIES

(WITH NOTES ON RAISING WEB BUILDING SPIDERS)*

By Michael H. Robinson and Barbara Robinson

Smithsonian Tropical Research Institute, P.O. Box 2072, Balboa, Canal Zone (Panama).

\title{
INTRODUCTION
}

"It is both expensive and difficult to maintain a year-round colony of mantids and a continuous supply of living insects upon which to feed them. Because of their cannibalism, mantids must be raised in individual containers, and the smaller males are invariably in short supply." Roeder, 1963, p. 141.

We think that we have found the solutions to these problems. We have devised a simple and inexpensive culture regime and found a species that is easy to manage in captivity. This species, Acanthops falcata Stol, is small enough to raise in large numbers in a modest amount of space and large enough to be convenient for a wide number of biological investigations. Females that are sexually receptive can be triggered to mate by a dark/light transition and males also become sexually active following such a transition. Matings are thus readily manipulable by the experimenter. In addition, the species is fecund and hardy.

Our interest in solving the problems of raising predatory arthropods began in 1971, when we needed naive predators in order to investigate instinctive behavior. We used two species of araneid spiders, Argiope argentata and $A$. aemula, feeding them on dead drosophiloid flies (Robinson \& Robinson, 1976a). Since then we have raised several generations of $A$. argentata and successfully hand reared two other species of web building spiders from egg cocoons, without the restriction of using dead prey, which makes the problem simpler.

*Manuscript received by the editor September 8, 1978. 
Later we became interested in the developmental biology of sexual size dimorphism and intrasexual size poymorphism (Robinson \& Robinson, 1976b, Robinson, B. \& M. H. Robinson, 1978). However, orb-weaving spiders are not easy subjects for this type of study, and we turned our attention to mantids, in particular to the dead leaf mantid, Acanthops falcata. A. falcata proved to be an ideal subject and could become a most useful laboratory animal. It is an extremely efficient predator, attacking, at all instars, any live prey from drosophiloid flies up to insects of almost its own size. In captivity it becomes very 'tame' and will wait for food to drop when the cage lid is raised, and will often take food directly from the forceps. Although the species has to be raised in separate cages, the containers we used were small, inexpensive, readily available and easily manageable.

We think that $A$. falcata has great potentialities as an experimental animal. It has an extensive behavioral repertory, with an efficient predatory strike and a complex startle display (first described by Crane, 1952). We have demonstrated (Robinson \& Robinson, in prep.) that receptive females secrete an attractant to which males fly. The pheromone remains to be isolated. The female has a relatively large head capsule and brain and the large eyes have excellent movement detection and depth perception. It should be an excellent subject for neurophysiological studies. Our success rate of rearing nearly 1,000 individuals over several generations has been about $95 \%$, and out methods should prove of interest to ethologists, neurophysiologists, biochemists and developmental biologists wishing to work with this mantid.

\section{Culture Methods}

THE INSECT.

Acanthops falcata is a small neotropical mantid of the family Hymenopodidae. For a mantid it has an unusual degree of sexual dimorphism. The flightless female (Figure 1) resembles a curled dead leaf and weighs $400-500 \mathrm{mg}$. The male, which flies well, resembles a flat dead leaf, and weighs under $200 \mathrm{mg}$.

A brief summary of the life history is given here. Details of instar duration, sizes and weights at each instar, variability of number of instars and mating behavior are to be published separately (Robinson \& Robinson, in prep.). 


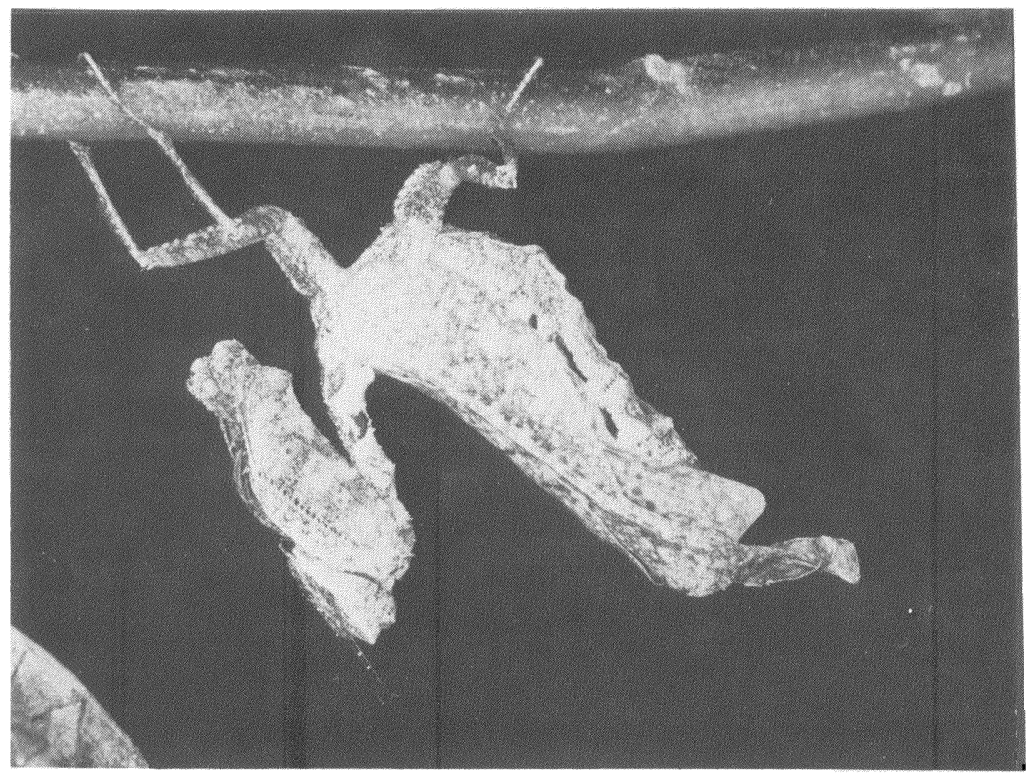

Figure 1. A fernale Acanthops falcata hanging from a twig in its cryptic posture. Body length $c a 45 \mathrm{~mm}$.

In captivity the females have a life expectancy of about 6 months. They lay long slender oothecae which may contain as many as 60 eggs, but more usually, 25-35. Eggs can be produced every 8 days and hatch in 16-19 days. We have records of females, that after one mating, laid 16 fertile oothecae. In Panama, at ambient temperature (about $25^{\circ} \mathrm{C}-30^{\circ} \mathrm{C}$ ), development from egg to adult is usually accomplished in 7 molts, including the molt from pronymph to first instar, that takes place at eclosion. Postembrionic development takes about 2 months, depending on food supply. We have kept males alive for over a month and for most of this time they remain sexually active. Even old males can be effectively mated. Unmated females secrete a pheromone for a limited period each day until they are mated. The period of secretion coincides with the brief daily period when males fly. In the wild, this period is immediately after dawn, but in the laboratory will occur after a dark/light transition (Robinson \& Robinson, in prep.). 
Cannibalism does not appear to be part of the mating behavior, as it is in many other species of mantids (Roeder 1935, 1963). Although males fall within the prey range of females, they seem to escape readily unless conditions are overcrowded. Copulations last from 20 minutes to 1 hour. After mating, the male drops from the female and usually survives to inseminate several females.

\section{THE CAGES.}

To raise large numbers of mantids in individual cages we made use of materials that are readily available and inexpensive. Transparent plastic party "glasses" need only a loose fitting cover to make a single plastic container into a cage. We found that the covers of plastic (disposable) petri dishes would fit one brand of $6 \mathrm{oz}$ shot "glasses" while the bottoms would fit another. These lids can be drilled to take a cotton ball insert that can be wetted to provide a high humidity within the cages. (In Panama's $80-100 \%$ relative humidity, this is not necessary.) The plastic cages can be stored on wooden trays, and stacked so that several hundred mantids occupy relatively little space. Fiber-tipped pens, sold as freezer markers, are excellent for marking index numbers and other data on the plastic cages. In natural conditions, $A$. falcata rests hanging from a thin twig. To provide a perch, we placed a piece of bamboo in each cage, resting diagonally from the top at one side to the bottom of the opposite side (Figure 2).

$6 \mathrm{oz}$ shot "glasses" are large enough for an adult female, but occasionally prove too small for an adult female to emerge successfully from the final molt. Ecdysis is diurnal, quick and usually without complications, taking about 30 minutes for all but the final molt, which takes about twice as long. As the majority of the insects ecdyse between $10 \mathrm{am}$ and $3 \mathrm{pm}$, we solved the cage size problem by watching individuals that were due to molt and removing them from the cage. Once molting had started, the stick with the molting mantid on it was placed in a piece of florists' clay or Play-Doh. Here the mantid ecdysed, turned and extended its wings. After a successful molt we returned the mantid, on its stick, to the cage.

We used several different cages in which to introduce males and fernales for mating. Out of doors we used a $2 \mathrm{~m} \times 1 \mathrm{~m} \times 1 \mathrm{~m}$ screened cage which was placed over several shrubs. Pheromone secretion by fermales, male flights and mating occurred only in the first 15 minutes after dawn. We also used a twelve gallon glass aquarium as 

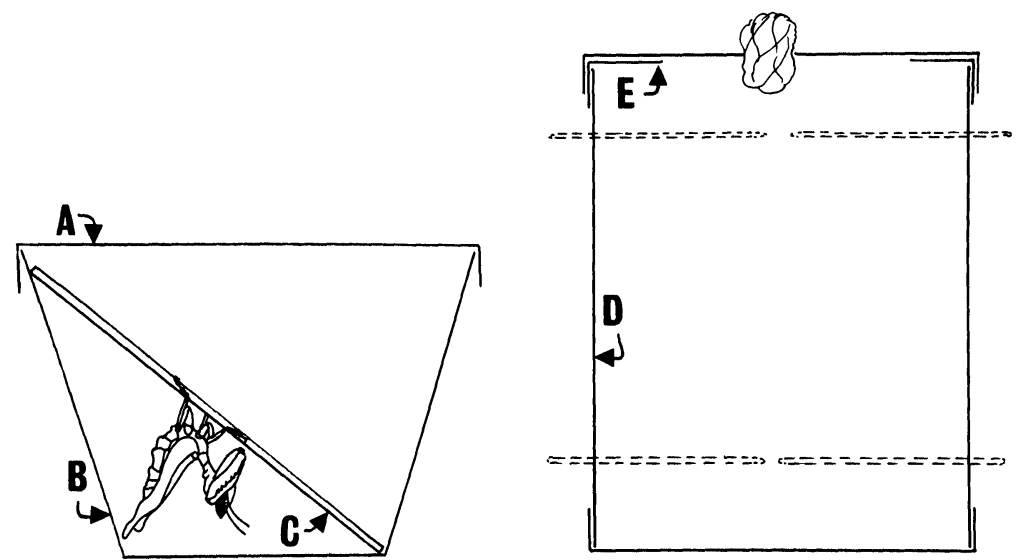

Figure 2. Left. Rearing cage for Acanthops falcata. (See text) A is a plastic petri dish and B a $60 z$ shot "glass". The fernale is shown in her resting posture on a piece of bamboo (C).

Right. A larger cage, suitable for spiders and large mantids. (See text) D is a cylinder of transparent acetate sheeting, $10 \mathrm{~cm}$ high, joined with cellulose tape. E shows the double lid made from a plastic petri dish and cover. The inner section has a hole of 5 cm diameter cut from it. The outer section, which is plugged with a moist cotton ball, can be raised to introduce food, without disturbing the animal. The positions of the cylindrical toothpicks which provide web attachment points and footholds are indicated.

a mating arena. This was fitted with a screen top and held two or three potted plants. In the enclosed space males seemed to have difficulty locating a secreting fernale and if males and fernales were left together in such a container outside the mating period, males were eaten. Several males can be left together, however, and females can be introduced when they are secreting. The aquarium had the advantage that the mantids could be kept in it in the dark, and we could initiate mating behavior without disturbing them, by bringing them into a lighted area. Later we developed a $1 \mathrm{~m} \times 1 \mathrm{~m} \times .5 \mathrm{~m}$ screened cage as a mating arena. Mantids from the dark phase of a controlled light regime can be brought into the light and released into such a cage, where they immediately become sexually active. Results are better if the light intensity is low. Since secreting females maintain a specialized posture (Robinson \& Robinson, in prep.) it is easy to determine when they are receptive. 
Fernales produce perfectly normal oothecae in the rearing cages. These are long and they hang down from the substrate to which they are attached by a long stalk. We removed oothecae from rearing cages, dated them and put them in $8 \mathrm{oz}$ clear plastic tunblers to hatch. To allow the pronymphs to emerge normally and complete their first molt on the outside, the ootheca must be attached to the lid of the hatching cage so that it can hang downwards, surrounded by free space. We tried various methods of attaching the ootheca stalk to the lid. This can be done with adhesive tape, but the small, fragile nymphs may stick to the exposed edges of the tape. It is more satisfactory to pass the stalk through a small hole and tape it to the outside of the lid. No additional moisture was necessary for most of the year in Panama, but during the dry season eggs were sprayed towards the end of the developmental period.

The pronymphs develop within the ootheca and at eclosion ecdyse to the first instar. They stand on the ootheca for several hours before dispersal and are easier to transfer to individual rearing cages at this stage. During the first instar they are not cannibalistic and can be kept communally but should be separated soon after the next molt.

\section{CULTURE TECHNIQUES.}

Normally mantids will not strike at motionless prey. The first three instars were fed exclusively on live drosophiloid flies. Sometime during the 4th instar the diet was changed to include live domestic crickets, Acheta domestica, supplied by Fluckers Cricket Farm, and by the 5th instar, only live crickets were fed. The Drosophila sp. were caught over a massive outdoor fruit culture in a fine meshed net, which was then placed in a freezer. By trial and error we determined the length of time necessary to immobilize the flies without killing them, and how long it took for them to become active again. The fastest way of introducing the flies into the cages was aiso the simplest. We transferred a quantity of immobile flies from the net onto a sheet of paper, and lifting each lid in turn, we shook the required number of prey into each cage. At the first instar this number was only two or three; towards the end of the fourth instar it was about ten. We quickly learned by experience how many mantids we could feed before the flies recovered on the paper, and, by looking at the cage debris, could tell if the mantids were under or overfed. The stage at which we changed the diet to crickets 
depended on the size of the crickets which were available. A. falcata will reach maturity entirely on a diet of Drosophila, but the developmental period is longer, and the adults that we raised on this diet were abnormally small (Robinson, B. \& M. H. Robinson, in prep.). To make the crickets easier to handle, they too were placed in a freezer for a short time, or stored in a refrigerator before being dropped into the cages from forceps. Uneaten crickets left in cages will eat ecdysing mantids or oothecae. The former is not a serious problem with $A$. falcata which molts during the day, as it is with species which molt at night, or whose molting time is longer. We have raised two other species of mantid, Phyllovates chlorophaea (see below) and Chaerododis rhombicollis (see Robinson 1969). Both these species were vulnerable to cricket attack for about two hours during each molt, which takes place at night. We had to remove live crickets from their cages at the end of each day.

In the humid tropics drinking water does not seem to be necessary for mantids that are fed daily. However, when they were transferred to the mating cages containing wet plants, they were observed to drink, males more than females. In air-conditioned or heated laboratories, it may prove necessary to supply moisture. As described above, cotton balls can be inserted into holes in the lids of the cages. These can be sprayed to keep them moist. Care should be taken that water does not form in droplets in the cages of first instar nymphs, as they will not be able to escape from the surface tension. We always use rainwater rather than tap water for spraying insects or providing moisture in cages.

\section{CAGES AND CULTURE TECHNIQUES SUITABLE FOR OTHER ARTHROPODS.}

We have also raised several other species of mantids successfully, using the above methods for small species. For larger species we used these techniques for early instars adapting them as necessary as the mantids grew too large for the cages. Phyllovates chlorophaea is a large, long-legged mantid, which we have raised successfully. For this large insect $6 \mathrm{oz}$ shot glasses were suitable until the 4th-5th instar. This species hangs below a leaf rather than from a twig. In order to give it a foothold on the lid of the cage, we attached a piece of masking tape, approx. $3 \mathrm{~cm}-5 \mathrm{~cm}$ to the undersurface. The cages that we used for later instars and adults are adaptations of lepidoptera rearing cages, designed by R. Silberglied and A. Aiello. 
These consisted of a cylinder of metallic hardware cloth, $10 \mathrm{~cm}$ high and with a diameter very slightly larger than that of a plastic petri dish. The petri dish fitted snugly inside the cylinder as a base, and a cover was placed over this, enclosing the bottom of the cylinder between the two. The top was bound with masking tape, and a second petri dish cover was used as a lid. Screened cages cannot, of course, be used until the mantid has transferred to a diet of crickets. For the final molt, when the mantid hangs from its exoskeleton until the legs harden, a $20 \mathrm{~cm}$ high cage was needed. Rather than build new cages for this very short period, two cages were joined together, by removing the base of the upper one and attaching it to the top of the lower one with masking tape. After ecdysis, the double cage was disassembled and the adult mantid was returned to its original cage.

Feeding procedures were exactly the same for $P$. chlorophaea as those described for $A$. falcata (above). However, either P. chlorophaea attacks smaller prey, or domestic crickets are not preferred prey. It was necessary to feed several small crickets daily, and to remove any uneaten prey at the end of each day. We raised $P$. chlorophaea to study its life history. It needs more care, more space and more complex cages than $A$. falcata. In addition, its mating behavior is similar to that of Mantis religiosa (Roeder, 1935), where males frequently do not survive to inserninate more than one fernale.

The lepidoptera rearing cage (above) can be modified so that live Drosophila can be fed, if the cylinder is made of transparent acetate sheeting. With the following modifications we found that they made excellent cages for raising web-building spiders, particularly those with horizontal webs. (See Figure 2.) The acetate cylinder was made to fit tightly into a plastic petri dish base. An inner lid was made by cutting a circle of $5 \mathrm{~cm}$ diameter out of a second petri dish, using an electric soldering iron. A petri dish cover was used as an outer lid. The outer lid, which was plugged with a cotton ball to keep the cage humid, could be raised for feeding the spiders, without disturbing web foundation lines. To give the spiders web attachment points, four cylindrical toothpicks were pushed through the acetate until they almost met in a cross, $2 \mathrm{~cm}$ from the top and $2 \mathrm{~cm}$ from the bottom of the cage.

We initially kept web building spiders in glass vials with snap caps (Robinson \& Robinson, 1976a). These are not ideal, as the web is often attached to the cap, and the spider cannot be fed without the web being damaged. Later we discovered the 1 inch diameter transparent plastic storage tubes, supplied by Forestry Supplies Inc. 
These come in 18 inch lengths, with separate plugs. They can be cut to the required size and fitted with a removable plug at each end. One cap was fitted with a moist cotton ball and either cap could be used to introduce food. Webs were rarely attached to both caps.

\section{FEEDING SPIDERS.}

Drosophila, the most readily available food, are probably larger than the natural prey of 2 nd instar spiderlings of most species and when used live usually break the fragile web and escape. Dead Drosophila placed in a spiderling's web are usually found and eaten soon after being introduced. If they are ignored at this stage, the spider feeds on them when the web is taken down. For later instars, prey of an appropriate size, immobilized in the freezer, can be placed or dropped in the webs. Spiders drink water from their webs, and even in the humid tropics, once the spider has been transferred from a vial to a cage we spray the webs with rain water daily.

We are (September 1978) presently undertaking a long research trip to Papua New Guinea and have given our culture of Acanthops falcata to the Insect Zoo, National Museum of Natural History, Smithsonian Institution, Washington, D.C. 20560, who hope to maintain it.

\section{REFERENCES}

Crane, J.

1952. A comparative study of innate defensive behavior in Trinidad mantids (Orthoptera, Mantoidea), Zoologica, N.Y., 37: 259-263.

Robinson, B. \& M. H. RoBinson.

1978. Developmental studies of Argiope argentata (Fabricius) and Argiope aemula (Walckenaer). Symp. Zool. Soc. Lond., 42: 31-40.

ROBINSON, M. H.

1969. The defensive behaviour of some orthopteroid insects from Panama. Trans. R. ent. Soc. Lond. 121: 281-303.

RoBinson, M. H. \& B. RoBINSON.

1975. Techniques in the field study of spiders. Bull. Brit. Arach. Soc., 3: 160-165.

1976a. Discrimination between prey types: an innate component of spider predatory behaviour. Zeit. f. Tierpsychol. 41: 266-276.

1976b. The ecology and behavior of Nephila maculata: a supplement. Smithsonian Contrib. Zool. 218: 1-22.

ROEDER, K. D.

1935. An experimental analysis of the sexual behavior of the praying mantis (Mantis religiosa L.), Biol. Bull. 69: 164-184.

1963. Nerve Cells and Insect Behavior, Harvard Univ. Press. 

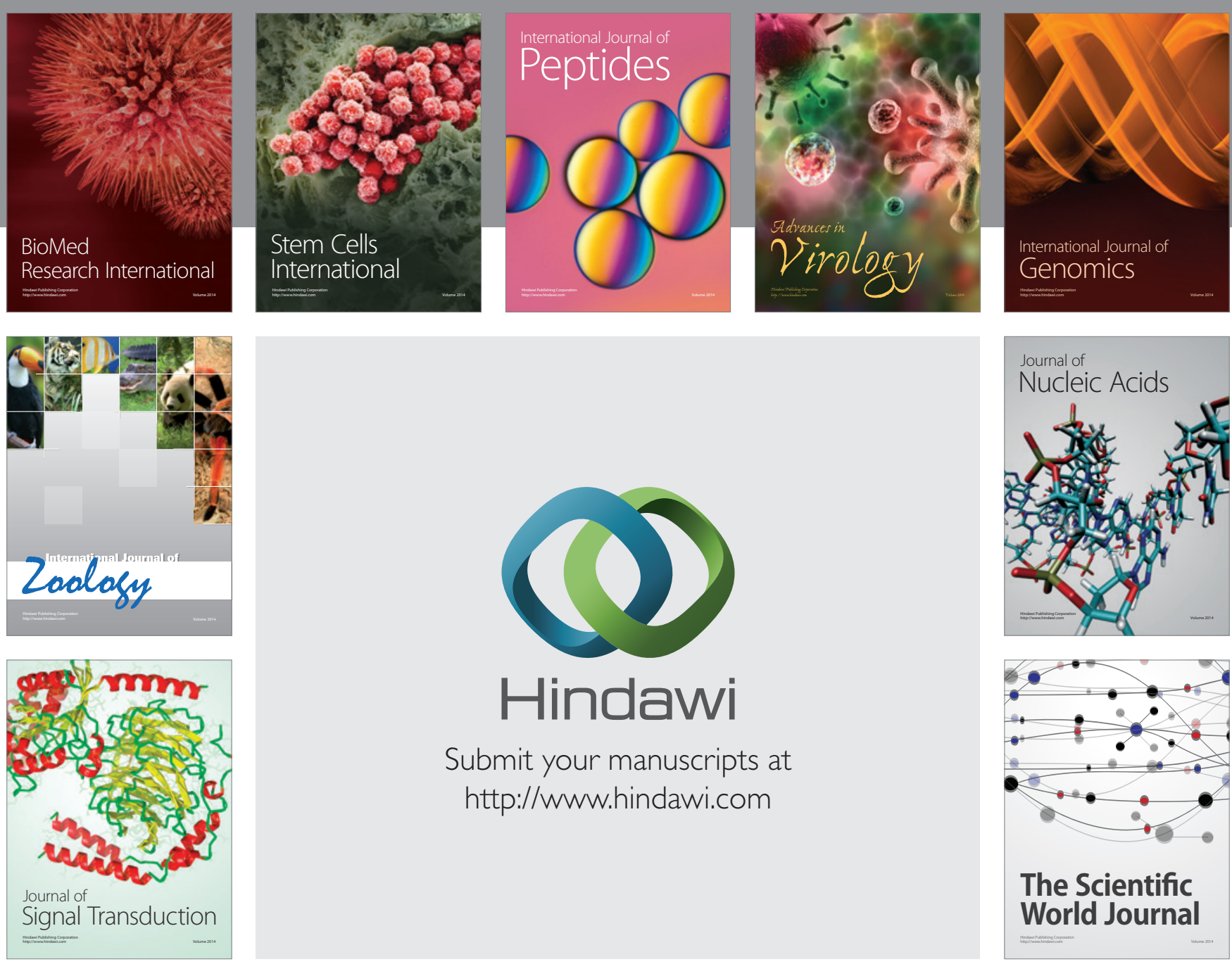

Submit your manuscripts at

http://www.hindawi.com
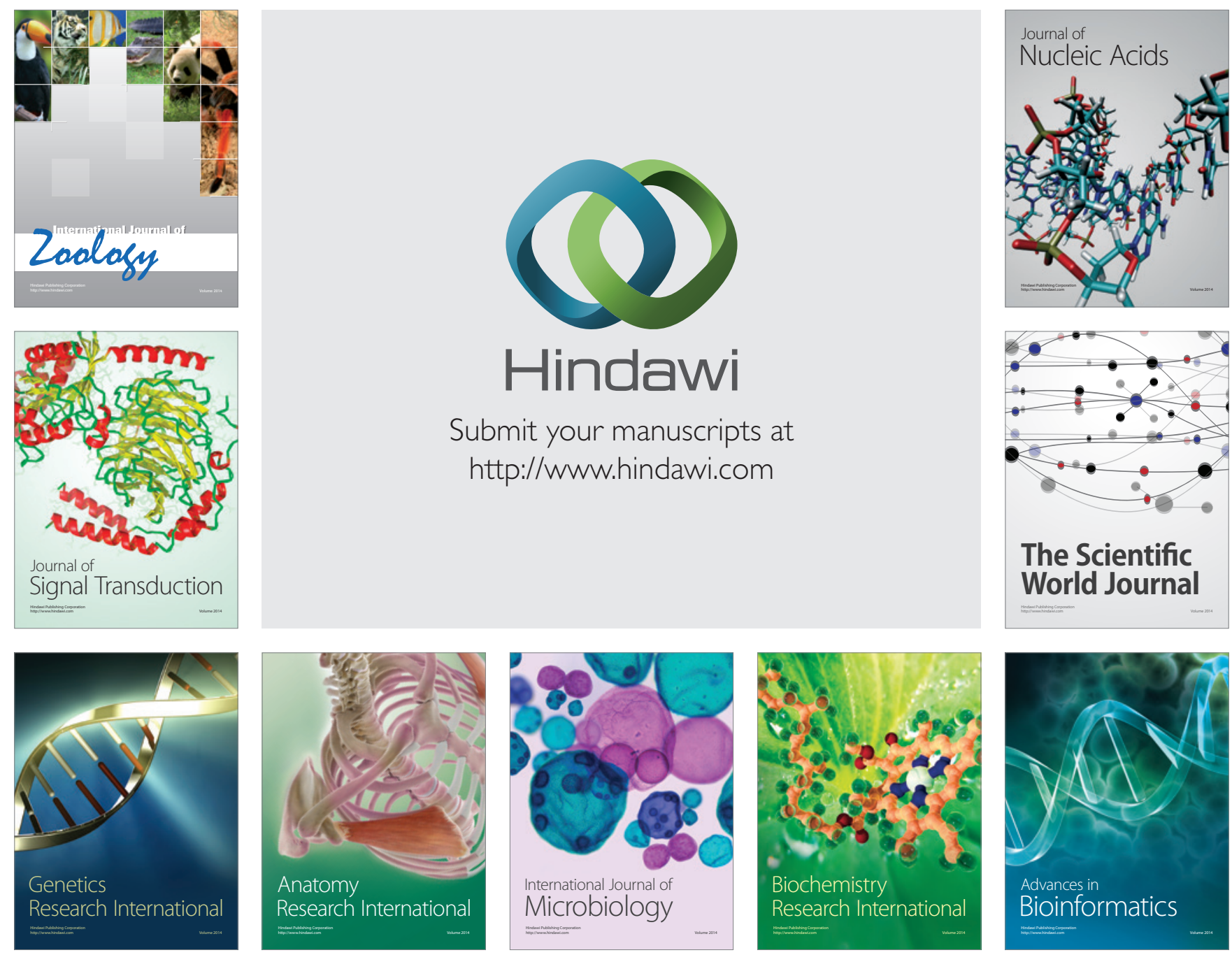

The Scientific World Journal
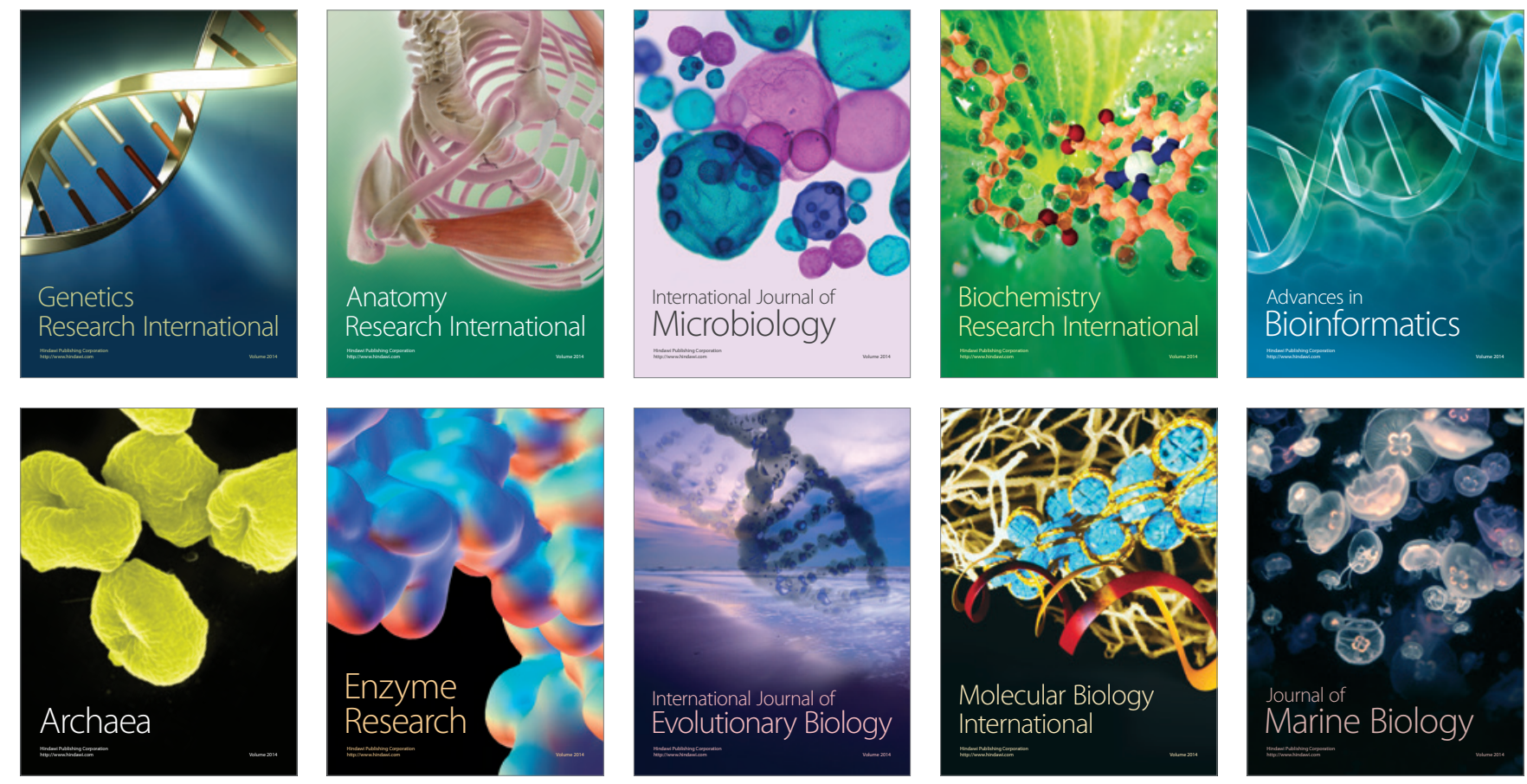